\title{
BMJ Open Challenges of developing, conducting, analysing and reporting a COVID-19 study as the COVID-19 pandemic unfolds: an online co- autoethnographic study
}

Roshan das Nair, ${ }^{1,2}$ Rachael Hunter, ${ }^{3}$ Afagh Garjani (1) , , ${ }^{1,4}$ Rod M Middleton, ${ }^{5}$ Katherine A Tuite-Dalton, ${ }^{5}$ Richard S Nicholas, ${ }^{5,6}$ Nikos Evangelou ${ }^{1,4}$

To cite: das Nair R, Hunter R, Garjani A, et al. Challenges of developing, conducting, analysing and reporting a COVID-19 study as the COVID-19 pandemic unfolds: an online co-autoethnographic study. BMJ Open

2021;11:e048788. doi:10.1136/ bmjopen-2021-048788

- Prepublication history for this paper is available online. To view these files, please visit the journal online (http://dx.doi. org/10.1136/bmjopen-2021048788).

Received 06 January 2021 Accepted 14 May 2021

\section{ABSTRACT}

Objectives To capture the complexities and unique experience of a newly formed multidisciplinary and multicentre research team developing and deploying a COVID-19 study and to identify lessons learnt.

Design Co-autoethnographic study.

Setting Staff at two UK academic institutions, a national charity and two major UK hospitals.

Participants Researchers, clinicians, academics, statisticians and analysts, patient and public involvement representatives and national charity.

Methods The sampling frame was any content discussed or shared between research team members (emails, meeting minutes, etc), standard observational dimensions and reflective interviews with team members. Data were thematically analysed.

Results Data from 34 meetings and $>50$ emails between 17 March and 5 August 2020 were analysed. The analysis yielded seven themes with 'Managing our stress' as an overarching theme.

Conclusions Mutual respect, flexibility and genuine belief that team members are doing the best they can under the circumstances are essential for completing a time-consuming study, requiring a rapid response during a pandemic. Acknowledging and managing stress and a shared purpose can moderate many barriers, such as the lack of face-to-face interactions, leading to effective team working.

\section{INTRODUCTION}

The COVID-19 pandemic resulted in hundreds of papers being published over the last year. The speed with which studies have been conceptualised, conducted and results disseminated has been impressive. Whilst this rapid delivery of research may be common for some specialities, for many (including us), the speed at which we had to work during the pandemic posed new challenges needing new solutions fast.

Only few COVID-19 studies have considered ethnographic approaches to understanding

\section{Strengths and limitations of this study}

- We had a good record of all emails and other messages the team exchanged, which served as rich source data.

- The COVID-19-MS study evolved very quickly, so the memories of key interactions and events remained fresh.

- Because we were all experiencing the same pandemic and UK lockdown, this created a shared understanding of our predicament.

- We started this study 1 month after the main COVID19-MS study began, so some data were possibly lost.

- We did not have a single ethnographer whose sole role was to record and interpret actions in real time.

phenomena of interest. Studies, for instance, have considered religious worship, ${ }^{1}$ crisis communication $^{2}$ and social experiences of lockdown, ${ }^{3}$ but none have focused on how a team is formed and works to develop and deliver a COVID-19 study.

This co-autoethnographic study covers COVID-19 and multiple sclerosis (MS) research. MS results in different degrees of disabilities. Many people with MS are prescribed disease-modifying therapies (DMTs). Early in the pandemic, clinicians were uncertain whether COVID-19 would disproportionately and adversely affect people with MS because of their disabilities or the immunomodulatory effects of DMTs. Various national (eg, Association of British Neurologists) and international (eg, MS International Federation) organisations offered guidelines on this topic but acknowledged that these were not based on empirical research. ${ }^{45}$ Therefore, there was an urgency for this gap to be addressed. 
National disease registries offer an opportunity to collect data from many patients quickly. We worked with the UK MS Register ('the Register') on the COVID-19-MS study. Launched in 2011 and funded by the UK MS Society, the Register collects real-world data from people with MS and National Health Service (NHS) sites across the UK. The Register can also rapidly deploy additional questionnaires to its participants. Therefore, it could host the COVID-19-MS study.

The COVID-19-MS study explored issues in biopsychosocial terms (eg, association between DMTs and COVID19 , impact of anxiety on MS symptoms and loneliness during the pandemic). This is an ongoing longitudinal study that follows up people with and without COVID-19 approximately fortnightly. The details of the study until April 2020 have been published. ${ }^{6}$ We have been updating and presenting the findings at national and international meetings, and further results have been submitted for publication.

Within this context, the rationale for conducting this co-autoethnographic study was to offer a reflexive and critical perspective of our own team working and to refine our ways of working; to keep a log of our own thoughts, feelings and experiences to enable us to work more effectively as a team; and to offer a product (this paper) to others who may find themselves in a similar situation in the future, and to help others develop more effective studies in other natural experiments or pandemics. ${ }^{7}$ Indeed, the value of such ethnographic research has been highlighted by Manderson and Levine, ${ }^{8}$ and we felt this was pertinent in the COVID-19 era.

\section{Aims}

Our aims were to:

1. Examine the process by which this national research on COVID-19 and MS unfolded in real time.

2. Explore the challenges the team faced at different stages of the research, as understanding about COVID-19 evolved, and the UK government reacted to this knowledge.

3. Identify lessons learnt that could prepare the research team (and others) in rapidly designing, conducting and disseminating similar studies during future waves of COVID-19 or other pandemics.

\section{METHODS}

'Ethnography is the study of social interactions, behaviours, and perceptions that occur within groups, teams, organisations, and communities. ${ }^{9}$ The emphasis is on exploring the nature of a complex social phenomenon, covering relatively unchartered territory, with multiple 'actors', and needing a deep understanding of the issues from within a system. In this case, the 'system' was the research team developing and delivering the COVID-19-MS study, and the 'actors' were ourselves as the researchers, who came from a range of disciplines (eg, neurology, psychology, research, and communications).
The in situ presence of the research team, acting as both participants and researchers, makes this an autoethnographic study. We also define this as an 'online' autoethnographic study because of the technology-mediated interactions necessitated by the restricted face-to-face contact during the pandemic, ${ }^{10}$ and 'co'-autoethnographic because the of the coconstructed nature of the ethnography, including mutiple authors. ${ }^{11}$ Autoethnography is a postmodern research method. Postmodernism rejects the possibility of having 'objectively' known 'truths' and recognises that multiple actors can arrive at different contrasting and converging truths (in plural), without privileging any one position. Autoethnography is linked to a hermeneutic phenomenological and social constructionist epistemology. Hermeneutic phenomenology relates to the subjective nature of experience and the meaning-making process that we engage in to make sense of phenomena, and social constructionism avers that all knowledge is developed ('constructed') and is socially situated and context dependent. ${ }^{12-14}$ It is beyond the scope of this paper to review the rationale and descriptions of autoethnographic research; we would like to refer the reader to Wall ${ }^{15}$ for an overview of autoethnographic research.

The sampling frame was everything we (the participants of this study) discussed or shared among ourselves during the COVID-19-MS study. Data sources included personal and collective memories and reflections, minutes and notes from meetings, observations made during meetings and emails related to the study. Newspaper articles communicating government decisions around the pandemic, and COVID-19 related publications were "cultural artefacts' (cultural artefacts relate to any 'objects' or human 'creations' that convey information and insights about daily life within a certain place and time) that we considered as additional sources to help contextualise our data. The lead author also led focused discussions with all team members individually to explore their views and perspectives on the research process. Triangulation was possible whereby we compared data or positions from multiple sources of data.

Standard observational dimensions of ethnographic research were followed: ${ }^{9}$ actor, activities, artefacts, events (activities that people carry out), time (sequencing of events), goals (what we were attempting to achieve) and feelings (emotions expressed). Because of the online nature of data, we could not observe space and objects, but noted people's kitchens (and their crockery), living rooms (and their bottle of wines), hospital offices (including personal protective equipment) and distractions (children and pets), and were alluded to during discussions.

Data analyses initially began in an inductive thematic manner. ${ }^{16}$ The primary reason for starting with an inductive analysis was, in line with Thomas, ${ }^{17}$ 'to condense extensive and varied raw text data into a brief, summary format'. Once the thematic structure was consolidated, we began to approach and seek data in a deductive manner 
that fit within our pre-existing themes, but we always kept an open mind for new themes to be elicited. This was enabled by being reflexive of our own and others' positions during data analyses and interpretation processes. Themes were corroborated by other team members, and any discrepancies were resolved through discussions and referral to the raw data.

We followed the ethical guidelines for autoethnographic research. ${ }^{18}$ All parties consented to participating and contributing to data collection, analyses, interpretation and write up of this study. We are unaware of specific guidelines for assessing and ensuring quality in autoethnographic research but have addressed the issues of rigour based on Le Roux, ${ }^{19}$ focusing on subjectivity, selfreflexivity, resonance, credibility and contribution.

Agreement for coding and themes was reached through discussions ( $\mathrm{RdN}$ and $\mathrm{RH}$ ), efforts to ensure triangulation was achieved through comparing the raw data, the emerging themes and related literature, and differences of opinion were resolved through discussion.

\section{Patient and public involvement (PPI)}

People with MS were consulted during a PPI meeting about the perceived value of this study. We have an MS PPI group that meets regularly. During such meetings, we discuss various MS studies that are being planned or ongoing and seek their input in terms of perceived value of the research and/or process when involving people with MS. One of our authors has MS and has shared their views as both a person with MS and as an academic/ researcher. As an autoethnographic study, we were both the researchers and participants.

\section{RESULTS}

Data from 34 group meetings comprising over $2000 \mathrm{~min}$ and over 50 emails between 17 March and 5 August 2020 were analysed. Results are organised thematically based on the temporal order of the study progress. The analysis yielded seven themes with 'Managing our stress' as an overarching theme.

\section{Developing the study team}

The COVID-19-MS study was supported by the Register's funding body (UK MS Society) who expedited funding within 2 weeks of receiving our proposal. Pre-existing relationships enabled rapid communications between the team and the funder. The initial study was a simple questionnaire designed by the Register team (RMM and KAT-D), in conjunction with a neurologist (RSN), in response to a blog posted on the Barts MS Blog, ${ }^{20}$ which is popular in the MS community. This questionnaire covered COVID-19 diagnosis, symptoms, sources of COVID-19 information for people with MS, DMT use, self-isolation practice and hospital admission. Another neurologist (NE) independently contacted the Register enquiring about setting up a COVID-19-MS study, and he and a research fellow (AG, who served as the primary clinical analyst) were co-opted into the team. At this stage, the study follow-up questionnaires were developed and launched. Then, a clinical psychologist $(\mathrm{RdN})$ contacted the Register to enquire whether psychological wellbeing could be captured in the next iteration of the survey. There was some initial reluctance among the largely medically-focussed team about including a psychologist; however, it was agreed that the study of psychological wellbeing would be valuable and that $\mathrm{RdN}$ would provide experience in large studies, ethics and analysis plans.

With a team that came together in an 'organic' fashion, with some people not having worked with others, there were research cultural differences, resulting in heated exchanges and delays in arriving at a consensus. An early bone of contention was the need for PPI in the study, with some members feeling this was crucial while others questioning it. A resolution was reached, and a PPI member (RH), known to the Register, was invited to join the team. The 'core' team was in place 13 days after the initial survey was designed. As the study evolved and data collection progressed, there was a growing consensus that engaging a statistician would have been/would be a useful addition to the team.

\section{Working together}

As a new team that had not worked together before, there was a period of adjustment to different people's personalities and styles of working. Communication between members improved once people adjusted to the online technology and each person began to appreciate the expertise others brought to the team. We began to recognise the pressures we were all working under, and the Register's standard operating procedures was clarified to all, in terms of what could be modified in the questionnaires and what was non-negotiable.

As members were from different academic disciplines, sometimes confusions arose simply because of the differences in academic 'languages' spoken. We overcame this by asking for clarification on how certain words were being used by different parties.

The team had two co-principal investigators (PIs) who had not previously worked closely together. There was no clear demarcation of their roles, so when disputes arose, team members tended to support each PI based on previous alliances. In such instances, it was helpful when a team member managed the conflict as independently and objectively as possible, keeping the team goal oriented. The issue of leadership was resolved over time, with their division of labour being discussed and agreed by the PIs outside of the whole team meeting. Despite these challenges, having co-PIs was helpful to ensure continuity of the study (when PIs had clinical or other responsibilities, or if one became ill, which was a concern during the pandemic).

Finding time to meet regularly was a challenge with some people working on the NHS frontline and others having new responsibilities because of the pandemic (eg, extra childcare), but a quick, agenda-driven meeting 
twice weekly at pre-arranged times was agreed. The online platform to 'meet' was mutually agreed (based on technology that was available for and familiar to all), and one person took responsibility for organising meetings and maintaining meeting notes. We also agreed on where documents could be stored and shared, how we would review and feedback documents such as the study protocol, analysis plan and manuscripts, and who had editorial responsibility of each document. This reduced issues with version control.

Outside meetings, members communicated with each other separately, advancing issues that they considered essential without input from other members. These interactions were triggered by the meetings and occurred mainly among members who had pre-existing working relationships or common professional interests, although not exclusively. These interactions reduced the time needed for full meetings and kept the agenda focused, but also, at times, resulted in actions that surprised other members not privy to these plans. Occasionally, this led to some members feeling that the 'team approach' to the project was being undermined.

We felt that some issues we faced were related to the technologies we were using. For instance, working together using online video conferencing and emails did not facilitate team building the way that face-to-face meetings would allow. However, this enabled coworking and increasing the frequency of meetings in a way that would have been impossible to arrange in-person (especially given the wide geographical spread of members).

\section{(Re)Designing the study}

The team were mindful that many of the standard 'rulebooks' for designing and conducting good quality research could not be applied in this research, because the study was being conducted during a pandemic evolving in real time. For instance, new symptoms of COVID-19 (eg, anosmia) were identified, ${ }^{21}$ which were not captured in our original questionnaire, and therefore, we had to rapidly revise it. Government guidelines for public behaviour changed over time, meaning that our initial questions quickly became redundant. However, we had already had responses from participants, so there were challenges in combining these data. The way the study and the pandemic unfolded in the UK is depicted in figure 1 .

Two months into the study, it became apparent that some details of the study were not fully agreed on by the whole team. Although the design had changed from a cross-sectional study to a longitudinal one, disagreements ensued about the nature of the follow-up questionnaires (whether they should remain unchanged, addressing issues identified at the study onset, or be adjusted based on the changing knowledge and needs).

Another issue was the limited testing for COVID-19 across the UK. When the study began, only those admitted to hospital were tested. Therefore, clinical confirmation of who was COVID-19 positive was a challenge. The team

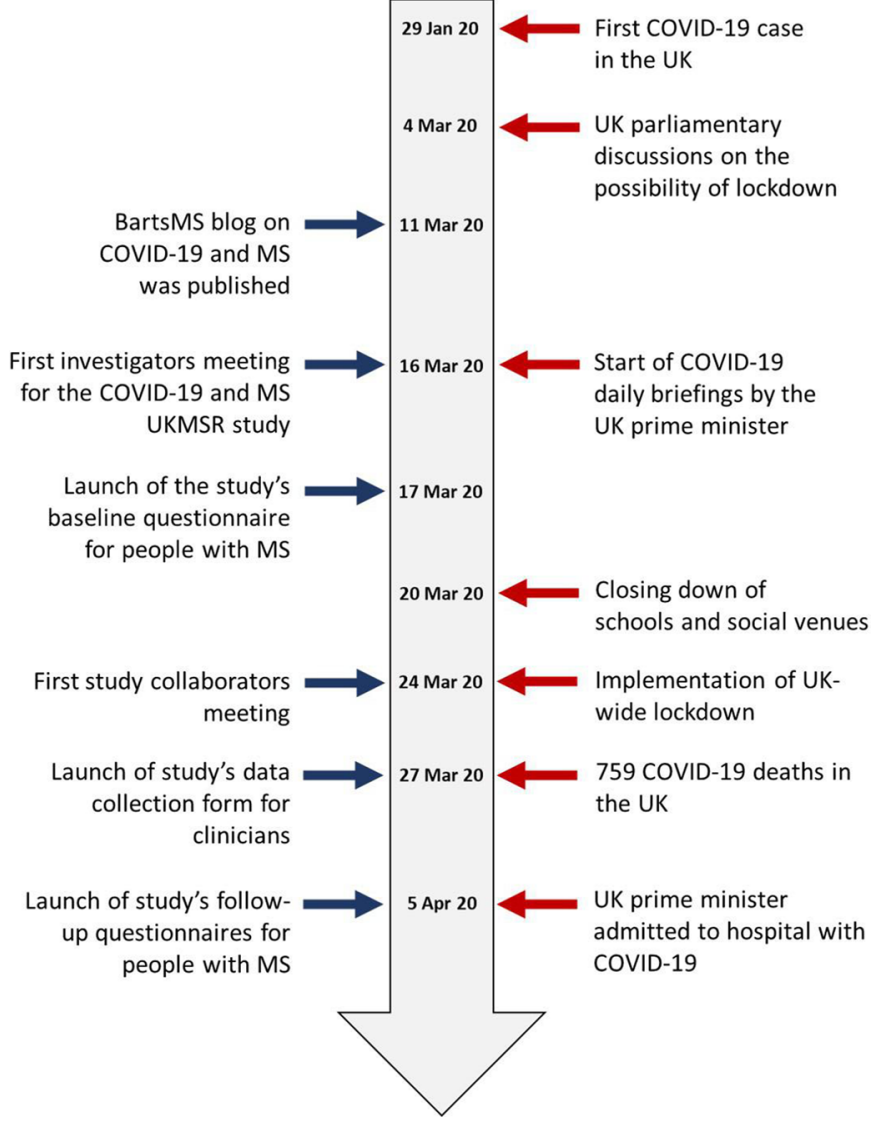

Figure 1 Timeline of the COVID-19-MS study and the pandemic with national/government guidelines and events depicted on the right and study developments on the left. MS, multiple sclerosis.

agreed to address this by asking respondents: (1) about COVID-19 symptoms, ${ }^{22}$ (2) whether they had been tested for COVID-19 and (3) whether a healthcare professional had made a clinical diagnosis. Additionally, a neurologist telephoned a sample of participants to confirm their symptoms and clinical diagnosis. We also requested clinicians at all UK MS centres to report anonymised data of those diagnosed with COVID-19.

\section{Conducting the study}

One big advantage was the existence of the Register, which had systems and staff in place to host new studies that helped us to act quickly. However, because the Register mainly supported studies that were planned, agreed and fixed months in advance of survey deployment, this new way of working (that required several changes being made in a very short time) caused some tension between the Register staff and other team members. The Register staff had to schedule this new study while ensuring they completed other planned studies. The speed with which the pandemic was spreading added further pressure. The Register staff were also concerned about questionnaire fatigue among respondents, so were reluctant to introduce additional questionnaires in case it adversely affected future response rates. 
The Register had general ethical approval from the UK NHS Health Research Authority to contact registrants with new questionnaires. Additional ethical approvals for non-MS 'control' groups were obtained through university ethics committees, who had established fast-track appraisals for COVID-19 studies. The implementation of these new policies during the COVID-19 pandemic enabled us to quickly deploy additional questionnaires.

As the study progressed, we observed gaps in the questionnaires caused by emerging issues due to the pandemic or government restrictions, and gaps in our own expertise (eg, there were reports of increased domestic abuse, ${ }^{23}$ but we did not have anyone in our team with expertise in this field). While there were important questions to be asked, we were concerned about 'mission creep' and its impact on respondents who would face longer questionnaires, risking respondent fatigue. There was also concern about the impact of adding new collaborators on the fragile equilibrium that the new team had just achieved. A compromise was reached by having an expert advisory team who would meet monthly and offer external scrutiny to the conduct of the study, provide feedback and help interpret findings.

Another challenge was that clinicians within the team were busier than usual, managing both their routine clinics and frontline work. This made them less available for research meetings and tasks (eg, telephoning respondents). We had funding to appoint new staff, but due to cashflow problems at universities and hospitals, there was a staff recruitment freeze. We considered offering consultation fees for system analysts for specific tasks to be completed, but the time taken to train them would not have made this a feasible option.

Some people with MS became ill with COVID-19 and were hospitalised. Therefore, there was a possibility that this group and those who were very ill either do not respond to the questionnaires at all or drop out after the baseline questionnaire. This would have skewed responding. We attempted to address this by following up the Register participants and by complementing our patient-reported data with clinician-reported data.

\section{Analysing data}

The changes we made to the questionnaires created challenges in merging data from their original and later versions. We were, however, able to do this because all our data were time-stamped through the Register system.

Once the data coding was revised based on the merged questionnaires, the analysis was hampered by the data analyst contracting COVID-19. However, because we had assigned deputies for each task in the project, we were able to continue with data cleaning and analysis with minimum delay.

Good practice dictates that healthcare research have a documented analysis plan before they begin. ${ }^{24}$ However, this was not entirely possible, because although the primary research questions were clear, additional questions were emerging as the pandemic and government restrictions unfolded. Therefore, some aspects of the analysis plan had to be modified, leading to certain risks (eg, over-analysing).

The speed of funding approval allowed for dedicated analyst time to be funded. Without this, it would have proven difficult to complete the analysis within the rapid pace of the study timeline. The study data generated were made available for analysis to two to three individual analysts and all members of the team. The analysis was done using various statistical software by different analysts producing almost identical results. This reinforced the reliability of the findings.

\section{Interpreting data}

While not having a 'control group' for aims specific to MS (eg, DMT use) was not a problem, other generic aims (eg, impact of self-isolation) needed a non-MS cohort. This was a challenge because the Register only includes people with MS. We resolved this in two ways, we: (1) contacted researchers conducting population-based, disease nonspecific COVID-19 research collecting comparable data (eg, mood questionnaires) to share their data and (2) obtained additional ethical approval to request the Register's respondents to send the questionnaire to people they believed not to have MS. In the former case, while some researchers responded positively, others were less receptive of collaborating. Engaging with other researchers also raised the question of who counted as a collaborator and who would earn co-authorship.

A further complication arose with public reports of the changing symptom cluster of COVID-19, with the public becoming aware of such new symptoms increasing the risk of hypervigilance and over-reporting. This could have resulted in increased false-positive diagnosis, particularly when based on subjective symptoms and in the absence of objective tests to confirm COVID-19.

\section{Reporting our findings/data sharing}

One of our aspirations was to provide the MS community with regular updates of our findings (as the project was born out of the need for immediate data-driven answers). This was important in such a longitudinal study, where ongoing participation is vital. However, it caused several challenges: (i) we needed dedicated staff to clean and analyse the data while performing all other tasks of the study. (2) We needed to determine how best to disseminate the data. With PPI input, we decided to produce short videos of the results, distributed on YouTube and the Register every fortnight. (3) The results were not peer reviewed, so we opted to provide mostly descriptive data, staying close to the raw data. (4) We needed to balance the risks of sharing data and losing ownership. Early on, we encountered an instance where our data were used without attribution to us. Therefore, we decided to register our study on ClinicalTrials.gov (NCT04354519) and include our branding and a statement of copyright on all our outputs. We were concerned whether our 
findings would be published in a reputable journal if they were already in the public domain.

We were clear from the outset that we wanted to share our data and methods. Therefore, on the day the original survey was launched, the Register shared the data dictionary with delegates of the MS International Federation. ${ }^{25}$ This enabled other registries globally to use our questionnaires and coding framework, allowing for future crosscountry comparisons.

\section{Managing own stress}

We had no doubt that our stress during the pandemic (clinical and research work, additional family and childcare responsibilities, sickness, the lockdown, etc) impacted on our ability to conduct this study. Furthermore, as the team were spread so widely geographically, there were inevitable differences in pressure according to whom the pandemic was affecting more at different times. This pressure contributed to tension, that was most acutely felt in our interactions, and the level of tolerance we had for each other. This, combined with the time pressure of distributing the questionnaires, analysing the data and disseminating the results continually, created at times a tense atmosphere and inevitably led to some mistakes being made (eg, coding errors, later corrected).

We consider this an overarching theme because the impact of the stress could be found on every aspect of the study. Where disagreements emerged, these were attempted to be resolved through an informal majority

Table 1 The key issues encountered and recommendations for developing and conducting the study

\begin{tabular}{|c|c|c|}
\hline Theme & Issue & Recommendation \\
\hline \multirow[t]{3}{*}{$\begin{array}{l}\text { Developing the } \\
\text { study team }\end{array}$} & $\begin{array}{l}\text { Deciding on the team } \\
\text { members }\end{array}$ & $\begin{array}{l}\text { Even if organically developed, once the core team is formed, it would be helpful } \\
\text { to quickly identify what further input is needed and which professional or patient } \\
\text { groups to involve. Agree in advance the roles and responsibilities of each team } \\
\text { member and decide on whether or how new members will be approached or } \\
\text { included. Team members from different disciplines may make the study stronger, } \\
\text { but the team needs to be small enough to resolve conflicts and act quickly. }\end{array}$ \\
\hline & $\begin{array}{l}\text { Patient and Public } \\
\text { Involvement (PPI) }\end{array}$ & $\begin{array}{l}\text { Involve PPI early. Having pre-existing PPI members involved in disease-specific } \\
\text { research is helpful because they would have had the required training and } \\
\text { experience to be able to offer their input within high-pressure, fast-pace, research } \\
\text { encounters. PPI members can help develop a Plain English Summary and } \\
\text { comment on concerns about questionnaire fatigue. Develop one early, so that it } \\
\text { can be used for publicity to help improve recruitment, but also for funding bodies, } \\
\text { ethics applications and dissemination. PPI members also help researchers keep } \\
\text { the needs of the patient at the forefront. }\end{array}$ \\
\hline & Two people per role & $\begin{array}{l}\text { Having two people per role (eg, two neurologists, two psychologists, two Register } \\
\text { staff) created some differences in opinion, but also ensured continuity (in case } \\
\text { people became ill). While this doubling up of roles is helpful, clear primary and } \\
\text { deputy roles and responsibilities need to be agreed in advance of the study } \\
\text { commencing. }\end{array}$ \\
\hline \multirow[t]{2}{*}{$\begin{array}{l}\text { Conducting the } \\
\text { study }\end{array}$} & Survey platform & $\begin{array}{l}\text { Use pre-existing disease-specific national registers to host new studies where } \\
\text { possible; however, be aware that their pre-existing workload may delay new } \\
\text { studies. Where registers exist, consider whether they can be adapted to include } \\
\text { 'control' participants' data also (where this is not available as part of the register). } \\
\text { Where registers do not exist, consider developing local registries. Explore which } \\
\text { platforms (eg, REDCap and Qaultrics) have been recently used successfully by } \\
\text { members of your study team. }\end{array}$ \\
\hline & $\begin{array}{l}\text { Ever-growing } \\
\text { questionnaire - adding } \\
\text { new questions }\end{array}$ & $\begin{array}{l}\text { Be prepared for the questionnaire needing to change-so prepare for the } \\
\text { change-and reflect on what needs to be put in place to enable or facilitate the } \\
\text { change. There are bound to be gaps in questionnaires. Weigh up the benefits of } \\
\text { asking certain questions and the risks of increasing the length of the survey and } \\
\text { resultant respondent fatigue. Beware of and manage 'mission creep'. }\end{array}$ \\
\hline
\end{tabular}


vote. Where necessary, the two or three members who could not agree on specific points met outside of team meetings to find a compromise, which was then communicated to the team.

\section{DISCUSSION}

The motivation for this ethnographic study was borne out of: (i) the novelty of the experience for us working without a framework for developing and deploying a study during a pandemic and (2) our desire to share the lessons learnt through this process. Our reflections on developing and conducting the study, working together and managing stress, and producing and disseminating findings are captured as recommendations in tables $1-3$, respectively.

We were affected by the pandemic we were researching. We had to work within the restrictions and challenges to personal and professional life that the pandemic created. However, these pressures, the fast-paced responses required and the unique shared experience, undoubtedly, contributed to the drive and commitment required to maintain study continuity. Indeed, from starting our study in March 2020, we were able to submit our first manuscript for publication in June, with it being published in August. ${ }^{6}$
Effective interprofessional teamworking processes remain relatively unexplored..$^{26}$ The challenges of our research seemed to be moderated by the members' (or 'actors') shared lived experience of the research focus (the pandemic), despite their differences in professional backgrounds, research perspectives, etc. This co-autoethnographic study supports evidence that working towards a shared purpose may build trust and may contribute positively to team relationships through moderating conflict within teams. This is a team process rarely discussed in the literature ${ }^{2728}$ but does feature in Allport's Intergroup Contact Theory. ${ }^{29}$ This theory posits that contact between members of different groups can facilitate better understanding and reduce prejudice and intergroup conflict. Future research could explore the mechanisms through which common goals and shared experiences facilitate disparate team membership.

Given the multiple geographical locations of the team members, the quantity and quality of communication were impacted by 'space and time'. ${ }^{30}$ The online nature of the teamwork enabled us to bypass these geographical challenges but did not prevent the development of strong working alliances between members. This supports the

Table 2 The key issues encountered and recommendations for working together and managing stress

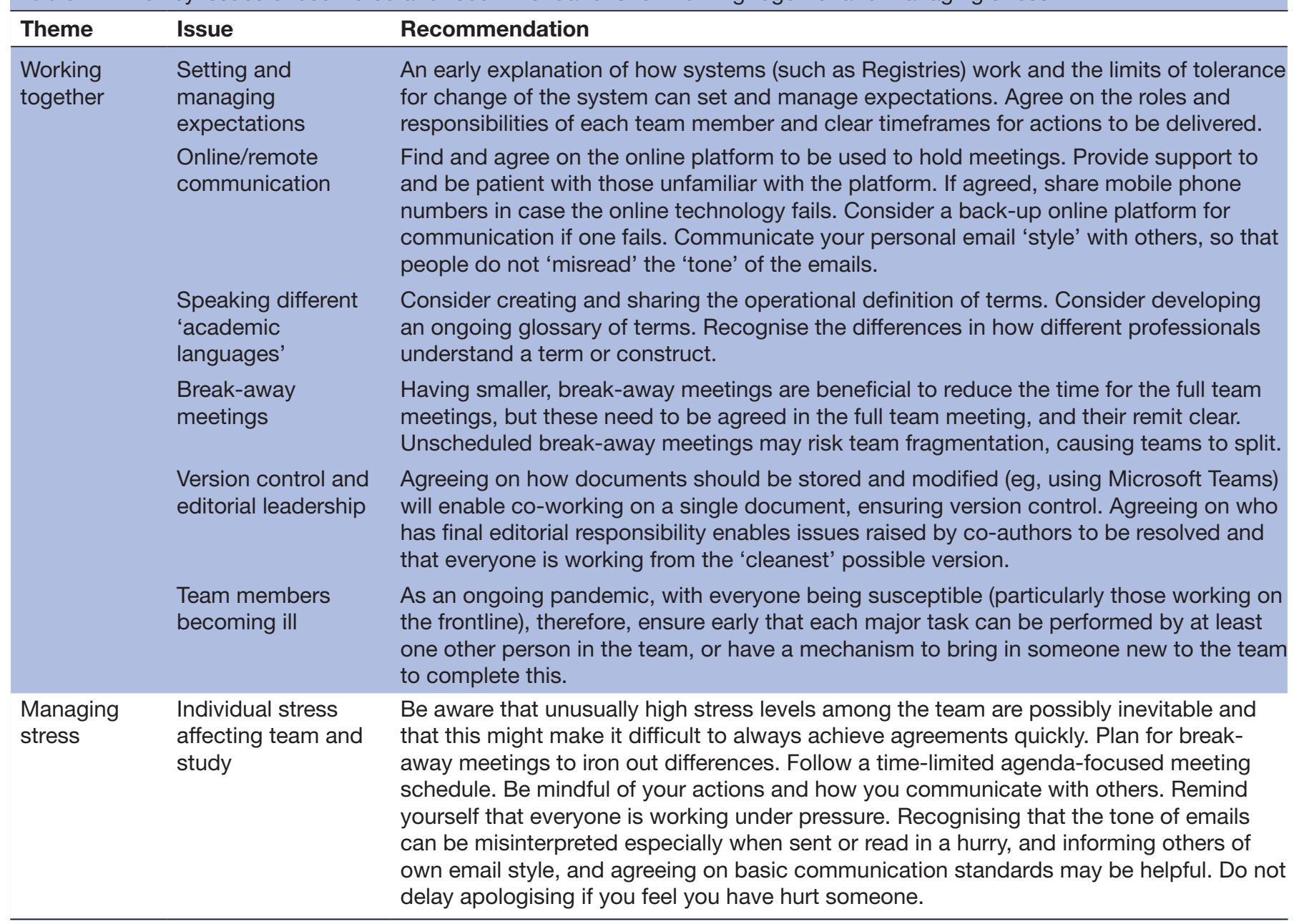


notion that online connections enable 'hyperpersonal' relationships even for multiprofessional teams in occupational settings. ${ }^{31}$ The implications of this are potentially far-reaching, for example, enabling the development of effective working collaborations that may not have previously been deemed possible nor effective. However, it should be noted that these interpersonal relationships were also influenced by projections of 'intentional identity', pre-existing relationships and smaller working groups outside the main team discussions, reflecting the multilayered nature of online team communications. Geach describes intentional identity as, "when a number of people, or one person on different occasions, have attitudes with a common focus, whether or not there actually is something at that focus' (p. 627)..$^{32} 33$

Our study highlighted differences of opinion among team members regarding the value and effectiveness of PPI. This points to a need to better understand, evaluate and disseminate research about the benefits and purpose of PPI. ${ }^{34}$ It seems essential that we expand our understanding of how such interpretations shape how user involvement is put into practice.

\section{Strengths and limitations}

The strength of this study was that we had a record of all messages we exchanged as a team, serving as rich source data. The COVID-19-MS study evolved very quickly, so the memories of key interactions and events remained fresh. Because we were all experiencing the same phenomenon, we developed a shared understanding of our predicament.

We started this study a month after the COVID-19-MS study began. Therefore, some data were possibly lost. However, this also meant that the participants did not modify their actions (a key criticism of such studies), and if they did, these modifications would have been noticed by others. We did not have a single ethnographer. Instead, we opted for a democratic way of having all 'actors' as researchers sharing and interpreting observations. Interestingly, this process engendered greater reflexivity and awareness within team members and improved our working relationships and wellbeing.

\section{CONCLUSION}

Some COVID-19 studies are done voluntarily (ie, without payment for some researchers) and are time consuming. This study suggests that mutual respect, flexibility, and genuine belief that team members are doing the best they can are essential ingredients for completing such studies during a pandemic.

Although sustained face-to-face team collaborations are regarded as essential for transforming a group of individuals into an effective team, this autoethnographic study

Table 3 The key issues encountered and recommendations for producing and disseminating findings

\begin{tabular}{|c|c|c|}
\hline Theme & Issue & Recommendation \\
\hline \multirow[t]{2}{*}{ Analysing data } & $\begin{array}{l}\text { Ever-growing } \\
\text { questionnaire - coding } \\
\text { and merging data }\end{array}$ & $\begin{array}{l}\text { Changes to surveys may be inevitable during an unfolding pandemic. Planning for how to } \\
\text { code changes and having all data time-stamped will enable merging and cleaning of data. }\end{array}$ \\
\hline & $\begin{array}{l}\text { Ever-growing } \\
\text { questionnaire - } \\
\text { managing data analysis }\end{array}$ & $\begin{array}{l}\text { Where possible, do have a draft analysis plan. It will add focus to the study, highlight } \\
\text { specific data needed to answer specific questions, will save time later during data } \\
\text { analysis, will restrict mission creep, and will result in a more robust study. }\end{array}$ \\
\hline \multirow[t]{4}{*}{$\begin{array}{l}\text { Reporting } \\
\text { findings/data } \\
\text { sharing }\end{array}$} & Ongoing reporting & $\begin{array}{l}\text { Have a clear dissemination policy and a plan for how, when and how frequently to release } \\
\text { data or report findings. Having PPI input at this stage is vital to ensure that the intended } \\
\text { patient group can understand the data. Be clear that the study is ongoing, so the findings } \\
\text { may change when more data accrue, and as the pandemic and resultant government } \\
\text { policies change. }\end{array}$ \\
\hline & $\begin{array}{l}\text { Protecting intellectual } \\
\text { property }\end{array}$ & $\begin{array}{l}\text { Register the study on an online study registry, like ClinicalTrials.gov. Have a clear copyright } \\
\text { statement and provide contact details of key authors to respond to data sharing requests. }\end{array}$ \\
\hline & Data sharing & $\begin{array}{l}\text { Consider having a data-sharing policy early on. The MRC has produced a useful } \\
\text { guide for researchers http://www.methodologyhubs.mrc.ac.uk/files/7114/3682/3831/ } \\
\text { Datasharingguidance2015.pdf }\end{array}$ \\
\hline & Authorship & $\begin{array}{l}\text { Having a plan for authorship at the start of the project is helpful. Use the International } \\
\text { Committee of Medical Journal Editors guidelines as a starting point http://www.icmje.org/ } \\
\text { recommendations/browse/roles-and-responsibilities/defining-the-role-of-authors-and- } \\
\text { contributors.html }\end{array}$ \\
\hline
\end{tabular}

MRC, Medical Research Council; PPI, patient and public involvement. 
suggests that acknowledging and managing stress, and a shared purpose, can moderate many barriers and create unlikely but effective team working. ${ }^{35}$

\section{Author affiliations}

${ }^{1}$ Mental Health and Clinical Neurosciences Academic Unit, University of Nottingham School of Medicine, Nottingham, UK

${ }^{2}$ Institute of Mental Health, Nottinghamshire Healthcare NHS Foundation Trust, Nottingham, UK

${ }^{3}$ College of Health and Human Science, Swansea University, Swansea, UK ${ }^{4}$ Department of Academic Clinical Neurology, Nottingham University Hospitals NHS Trust, Nottingham, UK

${ }^{5}$ Department of Population Data Science, Swansea University, Swansea, UK ${ }^{6}$ Department of Cellular and Molecular Neuroscience, Imperial College London, London, UK

Acknowledgements We would like to thank the participants of the UK MS Register and those who took part in the COVID-19 study. We would also like to thank all MS teams that have encouraged and supported people with MS throughout the pandemic at National Health Services sites across the UK.

Contributors RdN and RH conceived the idea of the study and were involved in the execution of the study and analysis of data along with AG, RMM, KAT-D, RSN and NE. The manuscript was drafted by RdN and RH, revised by $A G$, with intellectual contributions from all authors.

Funding This work was supported by the MS Society, grant reference number 131 Competing interests RdN is the Chair of the NIHR Research for Patient Benefit East Midlands Research Advisory Committee; he has received funding to prepare and deliver lectures on cognitive rehabilitation in multiple sclerosis from Novartis and Biogen. AG, RMM and KAT-D have received a grant from the MS Society as part of the UK MS Register. RSN has received support for advisory boards and travel from Novartis, Roche and Biogen. He has received grant support from the MS Society. He is a member of a NICE HTA committee. NE is a member of the advisory board for Biogen, Merck, Novartis and Roche. He has received grant income from the MS Society, MRC, PCORI and NIHR.

Patient consent for publication Not required.

Ethics approval Ethical approval for UKMSR studies was obtained from South West-Central Bristol Research Ethics Committee (16/SW/0194).

Provenance and peer review Not commissioned; externally peer reviewed.

Data availability statement Data sharing not applicable as no datasets generated and/or analysed for this study.

Open access This is an open access article distributed in accordance with the Creative Commons Attribution Non Commercial (CC BY-NC 4.0) license, which permits others to distribute, remix, adapt, build upon this work non-commercially, and license their derivative works on different terms, provided the original work is properly cited, appropriate credit is given, any changes made indicated, and the use is non-commercial. See: http://creativecommons.org/licenses/by-nc/4.0/.

ORCID iD

Afagh Garjani http://orcid.org/0000-0001-9271-346X

\section{REFERENCES}

1 Addo G. Worshipping on Zoom: a digital ethnographic study of African Pentecostals churches and their Liturgical practices during Covid-19. Malmö universitet/Kultur och samhälle, 2020.

2 Governmental Response to the COVID-19 Pandemic-A Quantitative Ethnographic Comparison of Public Health Authorities Communication in Denmark, Norway, and Sweden. ICQE (International Conference on quantitative ethnography) 2020, online, January 30-February 2, 2021. Aalborg University, 2020.

3 Zuev D, Hannam K. Anxious immobilities: an ethnography of coping with contagion (Covid-19) in Macau. Mobilities 2020:1-16.

4 Association of British Neurologists. ABN guidance on COVID19 and MS therapies 2020, 2020. Available: https://www.theabn.org/ news/492925/ABN-guidance-on-COVID19-and-MS-therapies.htm [Accessed 11 Dec 2020].
5 MS International Federation. Global COVID-19 advice for people with MS 2020, 2020. Available: http://www.msif.org/wp-content/uploads/ 2020/03/MSIF-Global-advice-on-COVID-19-for-people-with-MS docx-1.pdf [Accessed 11 Dec 2020].

6 Evangelou N, Garjani A, dasNair R, et al. Self-diagnosed COVID-19 in people with multiple sclerosis: a community-based cohort of the UK MS register. J Neurol Neurosurg Psychiatry 2020. doi:10.1136/jnnp2020-324449. [Epub ahead of print: 27 Aug 2020].

7 Craig P, Cooper C, Gunnell D, et al. Using natural experiments to evaluate population health interventions: new medical Research Council guidance. J Epidemiol Community Health 2012;66:1182-6.

8 Manderson L, Levine S. COVID-19, risk, fear, and Fall-out. Med Anthropol 2020;39:367-70.

9 Reeves S, Kuper A, Hodges BD. Qualitative research methodologies: ethnography. BMJ 2008;337:a1020.

10 Hine C. Virtual ethnography. Sage, 2000

11 Cann CN, DeMeulenaere EJ. Critical co-constructed autoethnography. Cultural studies? Critical Methodologies 2012;12:146-58.

12 Allen-Collinson J. Intention and epochē in tension: autophenomenography, bracketing and a novel approach to researching sporting embodiment. Qual Res Sport Exerc Health 2011;3:48-62.

13 Ellingson L, Ellis C. Autoethnography as constructionist project. In: Handbook of constructionist research. 445, 2008.

14 Reed-Danahay D. Auto/ethnography: rewriting the self and the social. Routledge, 2021.

15 Wall S. An Autoethnography on learning about Autoethnography. Int $J$ Qual Methods 2006;5:146-60.

16 Braun V, Clarke V. Using thematic analysis in psychology. Qual Res Psychol 2006;3:77-101.

17 Thomas DR. A general inductive approach for qualitative data analysis 2003.

18 Sikes P. Ethical considerations in autoethnographic research 2015 2020. Available: https://www.sheffield.ac.uk/polopoly_fs/1.586562!/ file/SREGP-Autoethnography-2015.pdf [Accessed 11 Dec 2020].

19 Le Roux CS. Exploring rigour in autoethnographic research. Int J Soc Res Methodol 2017;20:195-207.

20 The MS Blog. It seems that our experiment is going to happen by default, 2020. Available: https://multiple-sclerosis-research.org/2020/ 03/it-seems-that-our-experiment-is-going-to-happen-by-default/ [Accessed 14 Dec 2020].

21 Kaye R, Chang CWD, Kazahaya K, et al. COVID-19 anosmia reporting tool: initial findings. Otolaryngol Head Neck Surg 2020;163:132-134.

22 Menni C, Valdes AM, Freidin MB. Real-time tracking of self-reported symptoms to predict potential COVID-19. Nat Med 2020:1-4.

23 Campbell AM. An increasing risk of family violence during the Covid-19 pandemic: strengthening community collaborations to save lives. In: Forensic science international: reports. 100089, 2020.

24 Simpson SH. Creating a data analysis plan: what to consider when choosing statistics for a study. Can J Hosp Pharm 2015;68:311.

25 Multiple Sclerosis International Federation, 2020. Available: https:// www.msif.org/ [Accessed 14 Dec 2020].

26 Baxter SK, Brumfitt SM. Professional differences in interprofessional working. J Interprof Care 2008;22:239-51.

27 Firth-Cozens J. Organisational trust: the keystone to patient safety. Qual Saf Health Care 2004;13:56-61.

28 Jackson D. Collegial trust: crucial to safe and harmonious workplaces. J Clin Nurs 2008;17:1541-2.

29 Allport GW. The nature of prejudice: Cambridge. MA: AddisonWesley, 1954.

30 Oandasan IF, Gotlib Conn L, Lingard L, et al. The impact of space and time on interprofessional teamwork in Canadian primary health care settings: implications for health care reform. Prim Health Care Res Dev 2009;10:151-62.

31 Henderson S, Gilding M. 'I've never clicked this much with anyone in my life': trust and hyperpersonal communication in online friendships. New Media Soc 2004;6:487-506.

32 Walther JB. Computer-mediated communication: Impersonal, interpersonal, and hyperpersonal interaction. Communic Res 1996;23:3-43.

33 Geach PT. Intentional identity. J Philos 1967;64:627-32.

34 Fudge N, Wolfe CDA, McKevitt C. Assessing the promise of user involvement in health service development: ethnographic study. BMJ 2008;336:313-7.

35 Reeves B, Read JL. Total engagement: using games and virtual worlds to change the way people work and Businesses compete. Harvard Business Press, 2009. 